\title{
Exploring Pre-Service Teachers' Views Regarding Teaching for Transformation: A Proposed Autonomous-Transformative Framework for Higher Education Institutions
}

\author{
June M Palmer \\ School of Education Studies, Faculty of Education, \\ University of the Free State, palmerjm@ufs.ac.za \\ Micheal M van Wyk \\ Department of Curriculum and Instructional Studies, \\ School of Teacher Education, College of Education, \\ University of South Africa, Pretoria, vwykmm@unisa.ac.za
}

\section{Doi:10.5901/mjss.2013.v4n13p463}

\section{Abstract}

Pre-service teachers' views on their autonomy experienced during practice teaching sessions in schools were investigated in order to determine the extent to which they are autonomous and transformative. The pre-service teachers participated in a qualitative study and were all completing their final year of study in the module, Education for Transformation (EFK112). Data yielded from the interviews revealed that pre-service teachers do not know how to be autonomous and were uncertain as to how to teach for transformation. In this regard, five themes emerged which emphasise pre-service teachers' desires to be empowered. However, they remain demotivated to contribute positively to transforming the school environment because they do not know how to use their autonomy to teach for transformation. Issues such as fostering positive emotions, motivation, capabilities, autonomy and how to teach for transformation motivated us to propose a framework for higher education institutions with the focus on empowering pre-service teachers to be autonomous and to contribute to a transformed learning environment.

Keywords: empowerment, transformation, autonomy, positive emotions, motivation, capabilities, pre-service teacher training, critical inquiry

\section{Introduction and Orientation}

Over the past two decades, researchers in the humanities and social sciences have shown a growing interest in exploring the concepts teacher autonomy and teaching for transformation. In this article, we locate our discussion on education within the broader framework of transformation. Autonomous teacher training imperatives for a transformative South African educational system will be discussed. In addition, the autonomy to teach for transformation as reflected in teacher training practices in a faculty of education will be analysed. In relation to this, we present the reflections of preservice teachers in the faculty regarding their views and experiences of their autonomy to teach for transformation during teaching practice sessions. This study advocates that pre-service teachers' emotional intelligence (EI) becomes an indispensible tool in their quest to teach for transformation in South African schools.

Jansen (2009) notes it is commonplace in the literature on transformation that the learner in the classroom is often the target of change. He poses a pertinent question when he asks: "But what about those who teach? Have they somehow come to terms with the politics of emotions in their own lives and can they therefore be trusted to engage young people in this most troubling of subjects - race, emotions and change?"

We argue our proposition that transformation is an inherently emotional process; therefore, the concept of El and how this skill may assist pre-service teachers to use their autonomy to positively engage in the transformation of the South African school context is crucial.

\section{Pre-Service Teachers Teaching for Transformation}

Alexander, Van Wyk, Bereng and November (2009) are of the opinion that the purpose of education alludes to the development of human capital towards meeting and achieving the individual and psycho-social needs of learners and 
communities. Education, broadly conceived, is seen as the means by which individuals are recruited to be members of a culture, and by which culture is maintained (Spindler 1974). Enslin and Pendlebury (1998) support this view that the transformation of education is imperative in the transformation of the broader society. Moreover, Botha (2002) asserts that educational change is required to provide equity in terms of educational provision and therefore promotes a more balanced view of South African society. In describing his experiences as the first black dean of education at the former all white University of Pretoria, Jansen (2009) notes:

To say that change is complex, challenging, and contested within recently deracialized and deracializing institutions is to almost understate the dilemma. It is emotionally, spiritually and psychologically taxing and transformational at the same time.(p.187)

It stands to reason that pre-service teachers at South African universities in particular, must assume a new role. Preparing pre-service teachers to teach necessitates building capacity and enhancing their capabilities to smooth the process of interaction between their ideas about teaching for transformation and their experiences of and exposure to the teaching realities in South African schools.

Therefore, this study advocates for a transformed state of the individual before teaching for transformation can take place. Whicomb, Borko and Liston (2007) reiterate that teacher education should be guided by a goal for transformation. For the authors, a transformative education offers alternative narratives that challenge pre-service educators' perceived views and enlarges or directs their circle of meaning. It does so in a manner that engages feeling and intellect, and relies in some way on an inner eye, an inner self (Whitcom et al. 2007). Important considerations underlie the pre-service teachers' capabilities in engaging in transformational teaching. In doing so, the background of the individual teacher needs to be considered and how he/she conceptualises his/her role as a transformational teacher. Beck (1993) refers to a working understanding of the reality of life in which the individual no longer seeks to uncover a pre-existing reality, but rather is actively involved in an interactive process of knowledge creation. Furthermore, Whicomb, Borko and Liston (2007) posit that in preparing pre-service teachers, they should be asked what kind of teachers they wish to become and what view of teaching allows them to live and teach better. Referring to the latter, Dyson (2003) contends that pre-service teachers need to be free from habitual thinking and habitual judgment and need to possess the ability to stand back and take a bird's eye view of the programmes they operate and then be willing, in a mindful way, to participate in their preparation to be good thinkers and judges in their own right.

In view of the current change in the educational climate on teacher training and development in South Africa, which are characterised as volatile, challenging and unstable, necessitates that institutions of higher learning rethink what knowledge and skills pre-service teachers require. One of the major considerations with regard to how teacher education evolves in South Africa is around the question of how pre-service teachers are prepared in our higher learning institutions. What pedagogies inform or guide our institutions commissioned with the responsibility of preparing teachers, especially in the pervasive climate of transformation in schools and in society? (Fleish 2002; Jansen 2009; Booyse et al. 2011). Concerning formal education systems, Booyse et al. (2011) note that the teacher and the learners are not only involved with the curriculum and teaching methods or the organisation of the classroom, but also with the rules, beliefs, knowledge and culture that learners transmit among themselves.

\section{Pre-Service Teacher Autonomy and EI}

Emanating from the above, Vieira (2007) contends that teachers need to be prepared to face more obstacles and dilemmas than they do in the more traditional ways of teaching. This means that institutions of higher learning need to prepare and equip pre-service teachers to be reflective practitioners and critical intellectuals, struggling for autonomy as a collective interest. In this regard, the author states that teachers as principal agents of teaching need to be part of the building environments in which teams of teachers, administrators and education experts collegially work to improve the redesign of the school and the curriculum, thereby increasing the power of teaching. Jimminéz Raya, Lamb and Vieira (2007) offer the following definition of autonomy:

...the competence to develop as a self-determined, socially responsible and critically aware participant in (and beyond) educational environments within a vision of education as (inter)personal empowerment and social transformation. (p.34)

For the purposes of this study it is pertinent to show to what extent pre-service teachers, on their path to discovering and sharing knowledge, while experiencing feelings of uncertainty and being exposed to a multiplicity of 
viewpoints are allowed to exercise autonomy in schools. The many roles being required of teachers forces us to reconsider pre-service teacher training, which traditionally has focused on teaching specific knowledge and processes, but not on basic personal and interpersonal competencies. These should provide the future teacher with sufficient autonomy to address his or her own ongoing learning, to solve problems common to the profession and to meet imposed educational objectives. In this study we advance the proposition that transformation is an inherently emotional process. Emotion was once the missing dimension in research on educational change. Schools, as with any organisation, are emotionally charged spaces, but the dominant literature on educational transformation continues to ignore the emotional dimensions of educational organisations (Jansen 2009). This article argues that, in teaching for transformation, emotionally intelligent pre-service teachers are more likely to identify and manage possible negative emotions, stress, and anxiety during the process with a positive outlook. Jordan (2005) argues that emotional intelligence will promote the use of constructive change strategies to cope with changes within the school and diminish the likelihood of the emergence of negative behaviour. Therefore, the concept of emotional intelligence (EI) and how it can complement the pre-service ability to manage the process of transformation and teach for transformation are explored.

There is evidence that El is a significant predictor of an individual's social and personal functioning (Extremera et al. 2005, Schutte 2001). In a study carried out with secondary teachers in England, it was observed that the teacher's El predicts the level of burnout. Brakett, Palomera and Mojsa (2008) confirm a recent study where a teacher's ability to regulate emotions is related to his/her perceived levels of depersonalisation, self-realisation and emotional wear (Mendes, 2003). At the same time, teachers with high El use more positive, well-adapted coping strategies when dealing with different sources of stress at school, thus experiencing greater satisfaction in their work. (Palomera et al. 2008).

We argue that it is important for pre-service educators to acquire emotion management skills in order to respond specifically to the educational setting's emotional displays and particularly to ensure that change initiatives succeed. In so doing, the educator is then better equipped to meet personal expectations and goals and align these with the goals of the school.

\section{A Critical Inquiry into Pre-Service Teachers' Quest for Autonomy in Teaching for Transformation}

The interviews with pre-service teachers revealed that they do not know how to apply teacher autonomy and were unsure as to how to teach for transformation in schools. In order for pre-service teachers to use autonomy to teach for transformation, we contest that higher education institutions should be able to assist students in becoming autonomous, as well as strengthening their abilities to teach for transformation. In this regard Maarman (2009) asserts that education institutions should help a person to develop the ability to think critically and creatively, solve problems, make informed decisions, cope with and manage new situations, and communicate effectively; thus, rendering them capable of being autonomous.

This study therefore aims to develop a framework for higher education institutions to assist pre-service teachers to use their autonomy to teach for transformation. To achieve our aim, we employ critical inquiry. Critical inquiry strives to engender self-reflective activity amongst individuals to bring about a clear articulation of arguments in an atmosphere of openness to overcome distortions generated within social institutions (Waghid 2002). If interpreted correctly, the latter implies that the social world is described and explained and that resources can be provided to both criticise and change this world. To establish change, critical inquiry helps us to develop an understanding of pre-service teachers' views on autonomy. Such an understanding has a practical purpose: to help people to change an unsatisfactory situation. The unsatisfactory situation we refer to is pre-service teachers' complaint that they do not know how to be autonomous or how to teach for transformation.

Critical inquiry is therefore relevant because it can be utilised to address unsatisfactory situations as mentioned above. In this regard the third dimension of critical inquiry can be useful. According to Waghid (2002:51) the third dimension relates to the organisation of action where the idea of communicative interaction should be considered as important. Here, interaction between pre-service teachers and higher education institutions should result in new knowledge which should be systematically incorporated into the processes of change. Drawing on the third dimension of critical inquiry, our proposed framework aims at bringing enlightenment and emanciptory change which can be utilised by higher education institutions in teaching pre-service teachers how to use their autonomy and how to teach for transformation.

To emancipate pre-service teachers to be autonomous and to teach for transformation is to help individuals to negotiate their own values, meanings and purposes, rather than to act on those of others. In this regard, Mezirow (1997) asserts that educational interventions are necessary to ensure that individuals acquire understanding, skills and 
dispositions that should be considered essential in autonomy and teaching for transformation. The issue of interventions was considered during interviews when pre-service teachers indicated a need for change from their existing experiences into modified values, beliefs, skills and abilities.

We advocate that higher education institutions should mentor pre-service teachers within intervention programmes where they are guided as to how to be autonomous and how to teach for transformation. The goals of the mentor should be to engender trust in his/ her charge, encouraging the student to develop his/her own voice, to form his/her own theories and to marshal his/her own teaching practices (Daloz 1986). The mentor (higher education institution) thus becomes the catalyst for pre-service teachers' identities that enable them to develop a new vision for themselves based on their own experiences, rather than on images they have absorbed from others (Drago-Severson 2004).

Emanating from our exposition, a critical inquiry into pre-service teachers' views on autonomy and teaching for transformation allows us to develop a framework that will enable higher education institutions to capacitate pre-service teachers to use their autonomy to teach for transformation. In this regard, we agree with Ramos (2006:184-185) who asserts that: "[s]tudents who are encouraged to take responsibility for their own work are more likely to set realistic goals, plan programmes of work, develop strategies for coping with new and unforeseen situations, evaluate and assess their own work and learn how to be more efficient learners in the future."

\section{Research Methodology}

\subsection{Research paradigm}

We adopted an interpretive qualitative methodology in which texts can be interpreted with special reference to the world in which it was created and which it is disclosing. During the interpretation of text, the researcher tries to absorb or get inside the viewpoint it presents as a whole, and then develop a deep understanding of how its part relates to the whole (Adams 2004). In order to develop a deep understanding (interpretation) of pre-service teachers' experience on autonomy to teach for transformation, we based our interpretation on the assumptions that human life can only be understood from within. In this regard, we focus on pre-service teachers' subjective experiences on how they construct the social world in which they interact, namely how they experience autonomy to teach for transformation. We also worked with the assumptions (Niewenhuis 2007) that reality is not objectively determined. In this regard we argue that by allowing pre-service teachers to share their experiences, there is a greater opportunity to understand the perceptions they have of the practice teaching activities in which they engage. Furthermore, we assume that we can offer a perspective of the situation in which pre-service teachers frequently find themselves, by providing insight into the way they make sense of their experiences. Thus, by interpreting pre-service teachers' experience, we were able to design a framework that would inform higher education institutions of how they can leverage the power of autonomy and strengthen the abilities of pre-service teachers to teach for transformation.

\subsection{Research design}

A narrative inquiry-based research approach was used to explore student teachers' views and experiences regarding the autonomy in teaching for transformation. Semi-structured interviews were designed and used to collect data for the purpose of this study. We reported the findings of pre-service teachers' attitudes towards using autonomy in teaching for transformation. As such, we collected and analysed primary data used from the transcribed interviewed data (Teddlie \& Tashakkori 2009; Creswell 2009).

\subsection{Sampling}

We interviewed two groups of ten students from 68 Baccalaureus of Educationis (B.Ed) student-teachers. These students were registered for the module Education for Transformation (EFT122) and consisted of Black and White thirdyear B.Ed students. The students were taught by the researchers over a 12-week period of two contact sessions of 55 minutes per week for the second semester of 2010. This research was done in the School of Education studies in the Faculty of Education, at the University of the Free State, South Africa. 


\subsection{Interviews}

An interpretive narrative inquiry-based approach using qualitative research methods was considered suitable because it involves an interpretive, naturalistic approach to the world. Qualitative researchers are motivated by an in-depth inquiry to study a phenomenon in its natural setting, to make sense of, as well as to interpret the phenomenon in terms of meanings and understanding constructed by people (Denzin 2005). Therefore, the real-life experiences of pre-service teachers regarding autonomy to teach for transformation are captured. The pre-service teachers to whom we refer are sixty-eight B.Ed students who study the module Education for Transformation (EFD122). Twenty students were interviewed by means of focus group discussions (FGDs). FDGs capitalise on group dynamics, and allow a small group of respondents into increasing levels of focus and depth on the key issues of the research topic. Interviews with the participants were conducted outside their usual environment in a neutral context in the form of face-to-face unstructured interviews (Terre Blance \& Kelly 1999; Bester \& Du Plessis 2010). The research interview was open-ended and conducted in an informal, non-directive way so as to allow the free flow of conversation.

\subsection{Research instruments and procedure}

The following data collection instrument was designed and used for the purpose of this study. Semi-structured interviews: A quota sampling $(n=20)$ was identified and randomly selected for the interviews. An interview schedule was designed to obtain data. Interviews $(n=20)$ were conducted and the responses recorded, transcribed and coded into themes. For the qualitative data, the content analysis method was used, as explained by Leedy and Ormod (2001). The data was coded, themes were found, and the data organised and defined according to the codes and themes; then interpretations were made. This process is described by Teddlie and Tashakkori (2009) as "data reduction," "data display," and "conclusion drawing and verification". The interviewees accepted the official invitations and 45 minute interview sessions were conducted directly at the end of the 12-week period of the semester module.

\subsection{Ethical considerations}

The study under scrutiny met the standards of trustworthiness which encompass notions of validity, reliability, anonymity and conformability. The pre-serve teachers were consulted in the planning of the research and in the definition of the research objectives. Before we could begin with the study, we obtained consent from the students. We explained the purpose of the study. We decided beforehand to use pseudonyms for the students who participated in the interviews of this study. We then explained the purpose of confidentiality to the students. The students agreed that we could use their information for the purpose of this study. The potential benefits of the study were articulated clearly and unambiguously (Beylefeld et al. 2005). We also ensured that we adhered to the original goals of the research and obeyed the rules of anonymity. Participants were also afforded the opportunity to articulate their views on the interpretation of their responses. Furthermore, we read widely to compare our analysis (Flick 1999; Thorogood 2005) with research conducted with reference to pre-service teachers' autonomy to teach for transformation and found that little or no research has been done in which students of the UFS have participated in a study of this kind.

\section{Results}

\subsection{Sampling}

Only sixty-eight $(n=68)$ B. Ed student teachers who were registered for EFT 122, Education for Transformation module, were selected as the proportional stratified sample for the study. The sample consisted of fifty-seven point one percent (57.1\%) Black and forty-two point nine percent (42.9\%) White students. Furthermore, $47.7 \%$ of the students were females and $52.3 \%$ were males. Both groups were taught by the researchers over a 12 -week period of two contact sessions of 55 minutes per week for the second semester.

\subsection{Themes emerged from focus group interviews}

Twenty students were interviewed by means of focus group discussions (FGDs). An open-ended interview schedule was designed to obtain data. Interviews were conducted and the responses recorded, transcribed and coded into themes. For 
the qualitative analysis process, the content analysis method was used, as explained by Leedy and Ormod (2001). The data was coded, themes were found, and the data organised and defined according to the codes and themes. Then, interpretations were made. Teddlie and Tashakkori (2009) describe the process as "data reduction," "data display," and "conclusion drawing and verification". The interviewees accepted the official invitations and focus group discussions of thirty minutes per interview session were conducted directly at the end of the 12-week period of the second semester module. From the analyses of participants' responses, five themes emerged. An analysis and discussion of the interviewees' responses are outlined below:

\subsubsection{Theme 1: Own vision for education}

Having a vision for education is central to school leadership, because vision is a source of motivation and energy. It powerfully shapes practice within a school community. Thus, vision needs to be understood, articulated and owned by the whole school community. It provides both a source of inspiration and a frame of reference for developing professional values (Ahanhanzo et al. 2006). The students envisaged a view of education as a platform for teachers and learners to question academic and life issues at school. Being allowed to pose questions, pre-service teachers feel that it will enable them to change their mindsets of the way they think about the world and issues that are part of their lives. Furthermore, Kashefian-Naeeini and Riazi (2011) postulate that learners' beliefs are important in demonstrating their predispositions towards autonomy. They claim that this affords them the opportunities to utilise the best possible methods, so that learners are prepared to handle anything that crosses their paths in life. In view of the pre-service teachers' own visions for education, some of the key extracts from the interview-transcripts are given below:

"Our vision is that education should be tailored in such a fashion that people acquire the necessary knowledge, skills, values and attitudes";

"Education should allow us to play a role in learners' intellectual abilities"; and

"Education should change mindsets of the way we think about the world and issues that are part of our lives so that we can be successful."

\subsubsection{Theme 2: The Successful Teacher}

A teacher can be considered successful when the most appropriate methods, materials, teacher characteristics and the context in which teaching and learning occur are combined with the intention to deliver effective teaching (Edelson \& Vallone 2002). Pre-service teachers indicated that they view successful teachers as individuals who are able to produce a product. This view implies that a successful teacher is able to bring out the best in learners and motivate them to excel academically. To achieve academic excellence, teachers should play a vital role in developing new programmes and activities to realise the aims of the institution. In this regard the pre-service teachers noted:

"A successful teacher is independent; a person who plans ahead, finds the best teaching practices and ensures that learners are successful"; and

"A successful teacher is autonomous in creating opportunities and supplies learners with the necessary tools so that they know how to deal with issues in certain circumstances."

\subsubsection{Theme 3: Autonomy}

According to Little (1995) and Kashefian-Naeeini and Riazi (2011), successful teachers should be autonomous in the sense of having a strong sense of personal responsibility for their teaching, exercising via continuous reflection and analysis the highest possible degree of affective and cognitive control of the teaching process, and exploiting the freedom that this confers. In congruence with this view of autonomy, pre-service teachers assert that autonomy means to have the self-esteem to perform duties in a free, yet responsible manner. Autonomous teachers are thus assertive during planning, organising and decision making. This implies that teachers should be independent and do things in their own way. The pre-service teachers substantiated their responses by indicating that autonomous teachers: 
"Know their learners the best and should be allowed to choose methods they think work best while teaching subjects, concepts or content"; and

"Have skills to deal with academic needs, disciplinary problems and life lessons; they take control of any circumstance, make independent judgments and are organised and empathetic."

\subsubsection{Theme 4: Capabilities to promote autonomy}

Littlewood (1997) notes that autonomous people have an independent capacity to make and carry out choices which govern their actions. As such, teachers' capacities need to be developed in order to promote their autonomy. The basic premise here, according to Ramos (2006), as well as Hoyle and John (1995), is that, because teachers are aware of the reason, time, place and way in which they conduct teaching practices, they have to acquire skills and updated knowledge as part of their teaching practice in order to promote their autonomy. In this regard, pre-service teachers mentioned that their capabilities in terms of decision making, planning, educational methodologies and methods, as well as strategies to implement the curriculum should be developed. They claim that the latter actions will afford them opportunities to act as autonomous teachers. The pre-service teachers indicated that:

"Collaboration with schools should be improved because it will lead to building good relationships with schools which, in turn, will raise self-esteem and commitment towards the profession"; and

"We should be engaged in the planning of activities and decision making."

\subsubsection{Theme 5: Teaching for transformation}

According to the Department of Education (1997: Chapter 1, Section 1.3), transformation in education aims "to contribute to the socialisation of enlightened, responsible and constructively critical citizens. Higher education encourages the development of a reflective capacity and a willingness to review and renew prevailing ideas, policies and practices based on a commitment to the common good". Another aim is "to contribute to the creation, sharing and evaluation of knowledge. Higher education engages in the pursuit of academic scholarship and intellectual inquiry in all fields of human understanding, through research, learning and teaching". In line with this policy, we argue that if higher education institutions develop the capacity of pre-service teachers, they will be able to use their autonomy to adhere to the principle of transformation. In this regard, education policy stipulates that higher education institutions should be responsible for the "development of professionals and knowledge workers with globally equivalent skills, but who are socially responsible and conscious of their role in contributing to the national development effort and social transformation" (Van Wyk et al. 2010; Department of Education 1997: Chapter 1, Section 1.12). In this regard, pre-service teachers indicated that:

"We should not be limited in our efforts to advise teachers, but should be capable of advocating knowledge and skills to schools during practice teaching";

"Schools do not allow students to teach beyond the boundaries that were set by them"; and

"Practice teaching is just a way of accumulating marks and good behaviour- for these reasons students seldom apply methods to teach for transformation."

In view of the themes that emerged from the interviews, it can be argued that higher institutions should lay the foundations for the development of a learning society which can stimulate, direct and mobilise the creative and intellectual energies of pre-service teachers towards meeting the challenge of teaching for transformation.

\section{Discussion}

In a study, in which they describe a four-branch model which includes emotional identification, emotional facilitation, emotional understanding and emotion management, Mayer, Salovey and Caruso (1999) cited in Moss (2005) state that the identification of emotions is the lowest level skill and management of emotions the highest. In fact, the authors cite research that indicates a direct relationship between the ability to assess emotion in oneself and the ability to assess it in others (Mayer et al. 2002). A growing body of evidence indicates that emotional intelligence is positively associated with work performance (Slaski 2001). However, a study undertaken by Donaldson-Feilder and Bond (2004) indicates that the 
very act of controlling or regulating emotions diminishes mental well being, performance and job satisfaction. By contrast, a willingness and capacity to experience emotions, as opposed to disavowing or repressing them, can be healing (Harris 2007). Motivation is that which provides the momentum for teachers to motivate their learners and activate the emotions of love, preservation, recognition, self-expression and freedom. Teachers need to act inspirationally and enthusiastically; be aware of their own emotions and those of the learners, display a positive mental attitude toward life and believe that their learners have the untapped potential to cope with and solve emotional problems that they may have with a smile on their faces. In this way,, learners can detect emotional wellness and strive to emulate it (Palmer \& Kocks-De Waal 2010; Calitz et al. 2001). Bar-On et al. (2007) report on the educational support system in South Africa and note that it is not uncommon to see $70+$ learners crammed into a single classroom with learner support material being often non-existent. In other in-depth interviews conducted with principals, the authors state that they often sensed that the principals lack motivation. It seems that many teachers do not have the ability to or, understandably, the motivation to deal with these issues. As one teacher bluntly put it: "Ge re na Tshepo" ('we do not have any hope'), let alone the motivation to teach (Bar-On et al. 2007). Educators face many challenges related to learners' social and emotional needs in their classrooms. Zins, Travis and Freppen (quoted by Salovey \& Sluyter 1997) state that the degree of success these professionals have in addressing issues such as low academic achievement, drug abuse, teenage pregnancy and violence depends on how well they can identify the most salient aspects of the situation and the subsequent decisions they make based on these judgments. Accordingly, pre-service teachers need to develop a framework to guide their daily decision-making within the real world of the school that is based on reflection and enquiry. Transformational leadership has been of particular interest to El enthusiasts, probably because transformational leaders have been personified historically as embodying qualities now appropriated by the various models of El. When speaking of transformational leaders, Dasborough and Ashkanasy (2002) stress that such leaders may have an unquestionable willingness to obey their leaders' instructions. They conceive transformational leadership to be a process of social interaction in which leaders and followers are highly connected, with inspirational, motivational and emotional elements.

\section{A Proposed Autonomy in Teaching for a Transformation Framework (ATTF)}

We offer a useful framework for pre-service teachers' autonomy that would inform higher education institutions on how they can leverage the power of autonomy and strengthen the abilities of pre-service teachers to teach for transformation.

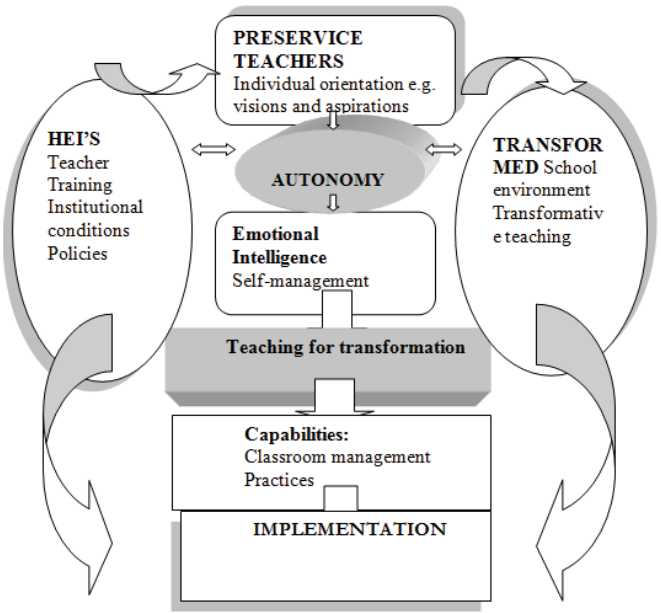

Figure 1. Autonomy in Teaching for a Transformation Framework

Emotions are produced by an interaction between cognitive appraisals, psychological changes and behavioural responses to external events. By taking charge of them, emotions are managed positively. Managing emotions appropriately is manifested in a person's ability to stay composed, positive and focused under pressure (Palmer \& KocksDe Waal 2010). Emotions are regulators of behaviour within us and in our interactions with others (Denham \& Burton 2003). For Hargreaves (2006) good teaching is charged with positive emotion. For the pre-service teacher, this implies 
not only knowing the subject content and being efficient, but having the correct competencies or learning the right techniques. They are motional, passionate beings who fill their work and classes with pleasure, creativity and joy. Therefore, with this framework we propose that pre-service teachers should experience self-management and selfdirection in their teaching, where development of the self increases their self-awareness as an imperative. The term selfawareness denotes ongoing attention to personal states, including emotion, a neutral mode that maintains selfeffectiveness, even amid turbulent emotions (Goleman 1995). In doing so, pre-service teachers are better able to understand the values and goals of the school and own a sense of responsibility for critical reflection on their practice. Interwoven with the theme of emotion, lies its motivational function. Different emotions are seen to be linked with different behavioural tendencies with a strong adaptive function which help the individual to adjust to the changing environment (Frijda 1986). Teacher training courses at HEls should provide an emotionally supportive context for teacher training with practical advice on strategies and classroom management in a transformational context which, in turn, leads to the true transformation in pre-service teachers' existing knowledge. Thiel (1999) points out that a supportive context for teacher training is a prerequisite for reflective practice, and reflection on teaching experience can foster pre-service teachers' autonomy. Pre-service teachers take the initiative to direct their teaching, building on the positive aspects and identifying areas where change is necessary. This, in turn, will create an environment which fosters intellectual openness where deep transformative learning takes place. Transformative learning theory (McGonigal 2005) recognises that changing one's perspective is not simply a rational process. Being forced to consider, evaluate and revise underlying assumptions can be an emotionally charged experience. This idea supports the motivational component that facilitates emotionally intelligent behaviour, individual performance and organisational productivity. David Wechsler (1940) described this over 60 years ago as "cognitive non intellective factors" which strongly contribute to intelligent behaviour (Wechsler 1958, as quoted by Bar-On et al. 2007).

With the capacity to understand and regulate their emotions, pre-service teachers, in teaching for transformation, are able to engage learners from diverse backgrounds and create classroom management practices of inclusion and direct their practice to stimulate and enrich each learner positively. For the researchers, this implies having the freedom for action in contributing to the transformative organisational culture in schools. Having the freedom to act or being autonomous does not imply not being accountable or doing as one wants, but fundamental to this freedom is the recognition of a sense of self, the development of the self professionally, in favour of learner autonomy so that teaching for transformation can take place. True change is not possible if it does not emanate from within. Reflecting on one's teaching practice to empower learners is a natural consequence of this acting with freedom. Thus, it is an imperative for higher education institutions to transform pre-service teachers in such a way that the positive self becomes the cornerstone of their interactions with learners and colleagues.

In this regard McGonigal (2005) opines that transformative teaching requires an environment that encourages and rewards intellectual openness. The transformative learning theory describes the conditions and processes necessary for pre-service teachers to make the most significant kind of knowledge transformation: a paradigm shift, also known as perspective transformation. Furthermore, Meizrow (1991) describes perspective transformation as the process of becoming critically aware of how and why our assumptions have come to constrain the way we perceive, understand and feel about our world; thus changing these structures of habitual expectation into a more inclusive, discriminating and integrating perspective and finally making choices or otherwise acting upon these new understandings. The implication therefore is that the teaching content will necessarily emphasise some strategies as more suitable than others (McGonigal 2005).

\section{Concluding Remarks}

Although researchers agree that emotional intelligence is a much needed competence, there seem to be many obstacles to its implementation, including training in schools and universities (Elias et al. 1997). Weisberg, Wang and Wallberg (2004) state that to successfully do so require the involvement and collaboration of the entire educational community. Higher education institutions therefore, are faced with the challenge of preparing pre-service teachers to become selfaware and to reflect on their own practice in teaching for transformation and to collaborate with other HEls, schools and the communities they serve.

\section{Limitations of the Study}

One must view the present study cautiously because of three limitations. The first limitation concerns the sample size 
which involved a small number of student teachers $(\mathrm{N}=68)$ who participated in this study. Because of the restricted range of participants, in future research studies, we hope to include a more diverse and representative sample of students from our faculty. The second limitation is the time factor. This study was conducted during only a twelve-week period of 55 minutes per contact session. A longer investigation period would possibly yield different results. The last limitation is challenges in changing and strengthening students' views on how to teach for autonomy in transformation.

\section{References}

Adams, N.D 2004. A Conceptual Analysis of Teacher Education in South Africa in Relation to the Norms and Standards for Educators. Unpublished PhD thesis,. Stellenbosch: Stellenbosch University.

Ahanhanzo, J., Odushin, B.E. \& Bibi-Adelakoun, A. 2006. Policy Dialogue and Education: African and Portugese experiences. Building a vision for Education in Benin. Prospects, 36(1): 9-21.

Alexander, G., van Week MM, Bereng T \& November IP. 2009. Legitimate Peripheral Participation (LPP) - The case for recognition of prior learning sites and knowledges in South Africa's transforming education system. Teaching and Teacher Education 26:4552.

Alkire, S. 2002. Valuing Freedoms: Sens's Capability Approach and Poverty Reduction. Oxford: Oxford University Press.

Bar-On, R., Maree, J.G \& Elias, M.J. 2007. Educating people to be emotionally intelligent: Johannesburg: Heinemann Publishers (Pty) Ltd.

Bester, S. \& Du Plessis, A. 2010. Exploring a secondary school educator's experience of school violence: a case study. South African Journal of Education, 30: 203-229.

Beylefeld A, Bitzer E \& Hay H. 2005. Action research: a wonderfully uncomfortable mode of creating knowledge. Acta Academia, 39(1): 146-175.

Booyse, J.J, le Roux, C.S, Seroto, J., Wolhunter, C.C. 2011. A history of schooling in South Africa. Method and context. Pretoria: Van Schaik publishers.

Calitz, L, Fuglestad, O \& Lillejord, S. 2002. Leadership in education. Cape Town: Heinemann.

Cohen, L., Manion, L. \& Morrison, K. 2009. Research methods in education. $6^{\text {th }}$ Edition. London: Routledge Farmer.

Costello, A.B. \& Osborne, J.W. 2005. The best practices in exploratory factor analysis: Four recommendations for getting the most from your analysis. Practical Assessment, Research and Evaluation, 10 (7), pp.234-254.

Creswell, J.W. 2009. Research design: Qualitative, Quantitative, and Mixed Methods Approaches. Third Edition. SAGE: Los Angeles.

Dasborough, M.T., \& Ashkanasy, N.M. (2002). Emotion and attribution of intentionality in leader-member relationships. The Leadership Quarterly, 13, 615-634.

Denham, S.A \& Burton, R. 2003. Social and emotional prevention and intervention programmes for preschoolers. New York: Kluwer Academic/Plenum publishers.

Denzin, N.J. 2005. The SAGE handbook of qualitative research. New York: Sage.

Department of Education 1997. A Programme for the Transformation of Higher Education (Education Draft White Paper 30. Pretoria: Government Printers.

Daloz, L. 1986. Effectice teaching and mentoring. San Francisco, CA: Jossey Bass Publishers.

Drago-Severson E 2004. Becoming adult learners: principles and practices for effective development. New York: Teachers College Press.

Edelson, P.F. \& Vallone, G. 2002. Staff Development in Critical Thinking Skills for Secondary School Teachers across the Curriculum: Definition and Concept-Development. Analytic Teaching, 22(2):125-135.

Elias, M., Zins, J., Weisberg, R., Frey, K., Greenberg, T., Haynes, N., Kessler, R., Schwab-Stone, M., \& Shriver, T.1997. Promoting social and emotional learning:Guidelines for educators. Alexandria, VA: Association for Supervision and Curriculum development.

Fleisch, B.D. 2002. Managing Educational Change. The State and School Reform in South Africa. Sandown: Heineman Publishers (Pty) Ltd.

Flick U 1999. An introduction into qualitative research. London: Sage.

Frijda, N.H. 1986. The emotions. Cambrige, New York: Cambrige University Press.

Gasper, D. 2002. "Is Sen's Capability Approach an Adequate Basis for Considering Human Development?" Review of Political Economy, 14(4):435-461.

Gasper, D. 2007. What is the capabilities approach? Its core, rationale, partners and dangers. Journal of Socio-Economics, 36(3):335359.

Goleman, D. 1995. Emotional Intelligence \&working with emotional intelligence omnibus. London: Bloomsbury Publishing.

Gorsuch, R.L. 1997. Exploratory factor analysis: Its role in item analysis. Journal of Personality Assessment, 68(3), pp. 532-560.

Green, J. \& Thorogood, N. 2005. Qualitative methods for health research. London: Sage.

Hargreaves, A. 2006. International handbook of educational change. London: Kluwer Academic Publishers.

Harris, B. 2007. Supporting the emotional work of school leaders. London: Paul Chapman Publishing.

Hoyle, E. \& John, P. 1995. Professional knowledge and professional practice. London and New York: Cassell.

Jansen, J.J. 2009. When politics and emotion meet. Educational change in racially divided communities. In Change Wars. Hargreaves, 
A \& Fullan, M. (eds.) p.185-199.

Jiménez,Raya, M. 2007. Developing professional autonomy: a balance between licence and responsibility. Independence 40: 32-34.

Kashefian-Naeeini, S \& Riazi, A.M. 2011. Beliefs and Autonomy: A Case of Iranian students. European Journal of Social Sciences. Vol 20, (3):425-430.

Knoesen, B., Truter, I. \& Stroud, L. 2009. Awareness of the potential risk of printed pharmaceutical advertisements. Acta Academia, 41(4): 74-91.

Leedy, P.D. \& Ormond, J.E. 2001. Practical research: Planning and design. $7^{\text {th }}$ Edition. New Jersey: Merrill Prentice-Hall.

Little D 1995. Learning as dialogue: The dependence of learner autonomy on teacher autonomy. System, 23 (2): 175-181.

Maarman, R. 2009. Manifestations of "capabilities poverty" with learners attending informal settlement schools. South African Journal of Education, 29(3): 1-11.

Mabovula, N. 2010. Revisiting Jürgen Haberma's notion of communicative action and its relevance for South African school governance: can it succeed? South African Journal of Education, 30(1): 1-12.

McGonigal, K. 2005. Teaching for transformation: From learning theory to teaching strategies. The centre for teaching and learning Vol 14 (2) Stanford University.

Mezirov, J. 1997. Transformative learning: theory to practice. In Cranton P (ed.). Transformative learning in action: Insights from practice. San Francisco, CA: Jossey-Bass Publishers.

Moss, M.T. 2005. The emotionally intelligent nurse leader. San Francisco: Jossey-Bass.

Niewenhuis, J. 2007. Introducing qualitative research. In Maree K (ed.). First Steps in Research. Pretoria: Van Schaik Publishers.

Nussbaum, M. \& Sen, A. 1993. The quality of life. New York \& Oxford: Claredon.

Oosterlaken, I. 2009. Design for Development: A Capability Approach. Massachusetts Institute of Technology Design Issues, $25(4)$ : 91 101.

Palmer, J. \& Kocks-de Waal, E. 2010. The impact of educators' emotional intelligence on managing change. A mixed method approach to gain South African insight. Germany: Lambert Academic Publishing.

Palomera, R., Fernandez-Berrocal, P. \& Brackett, M.A. 2008. Emotional intelligence as a basic component in pre-service teacher training. Journal of research in psychology. No 15 Vol 6 (2). pp 437-454.

Putman, L.L. \& Mumby, D.K. (1993). Organisations, emotion and the myth of rationality. In Fineman (Ed.), Emotion in organizations (pp.36-57). London: Sage.

Ramos, R.S 2006. Considerations on the role of teacher autonomy. Colombian Applied Linguistics Journal, 8: 184-202.

Robeyns, I. 2003. The capabilities approach: An interdisciplinary introduction. Amsterdam: University of Amsterdam.

Salovey, P., \& Sluyter, D. 1997. Emotional development and emotional intelligence. New York: Basic Books.

Schwandt, T.A. 2007. The SAGE dictionary of qualitative inquiry. $3^{\text {rd }}$ edn. London: Sage Publications.

Sen, A. 1985. Commodities and Capabilities. Oxford: Basil Blackwell.

Sen, A. 1999. Development as Freedom. Oxford: Oxford University Press.

Shulman, L. 2004. Theory, practice, and the education of professionals. In Wilson S

(ed.). The Wisdom of Practice - Essays on Teaching, Learning, and Learning to Teach (collection of papers by L. Shulman). San Francisco: Jossey Bass.

Smit, B. 2001. How primary school teachers experience education policy change in South Africa. Perspectives in Education, $19: 67-83$.

Teddlie, C. and Tashakkori, A. 2009. Foundations of Mixed Methods Research: Integrating Quantitative and Qualitative Approaches in the Social and Behavioral Sciences. SAGE: California.

Terre Blance, M. \& Kelly, K. 1999. In: Terre Blance M \& Durrheim K (eds.). Research in practice: applied methods for the social sciences. Cape Town: University of Cape Town Press.

Thiel, T. 1999. From trainee to autonomous teacher. The English teacher Vol XXV111. www.melta.org. Accessed 15 November 2010.

Van Wyk, B. 2003. Exploring the notion of Educational Transformation: In search of Constitutive Meanings. International Journal of Special Education, 18(2): 1-17.

Van Wyk, M.M., Alexander, G. \& Moreeng, B.B. 2010. Education for Transformation: A case of a Faculty. South African Journal for Higher Education (SAJHE), 24(6) pp 1036-1051. Unisa Press ISSN 1011-3487.

Viera, F. 2007. Teacher autonomy. Why should we care? Independence 41. 20-28. 
